Motrivivência Ano XXIII, No 36, P. 169-168 Jun./2011

doi: 10.5007/2175-8042.2011v23n36p169

\title{
O TRATO COM O CONHECIMENTO DA GINÁSTICA: UM ESTUDO SOBRE POSSIBILIDADES DE SUPERAÇÃO
}

Cristina Souza Paraiso ${ }^{1}$

\section{RESUMO}

O estudo apresenta como objeto proposições superadoras para o ensino da ginástica na escola, a partir da organização do trabalho pedagógico - trato com conhecimento. Visa explicitar possibilidades de alteração do trabalho pedagógico, no trato com conhecimento da ginástica na escola, a partir de uma pesquisa qualitativa analisando as obras: Coletivo de Autores (1992), Almeida (2005), Ayoub (2007) e o Livro Didático Público de Educação Física do Paraná (2006). Os resultados possibilitam reconhecer que, apesar das contradições evidentes, é possível contribuir para alterar o trabalho pedagógico a partir de determinados princípios e proposições superadoras no trato com o conhecimento da ginástica.

Palavras-chave: Possibilidades superadoras; Ginástica; Escola.

\section{Introdução}

O seguinte texto tem como objetivo apresentar uma síntese da dissertação de mestrado² que trata das proposições superadoras para o ensino da ginástica na escola, a partir da organização do trabalho pedagógico - trato com o conhecimento.

Estudos anteriores, como os do Coletivo de Autores (1992),

1 Doutoranda em Educação PPGE/UFBA e pesquisadora do Grupo LEPEL/FACED/UFBA. Contato: tinaparaiso@yahoo.com

2 Dissertação defendida no ano de 2010 no Curso de Pós-Graduação em Educação Física, Centro de Desportos, Universidade Federal de Santa Catarina na área de Concentração: Teoria e Prática Pedagógica em Educação Física, tendo como orientador o Prof. Dr. José Luiz Cirqueira Falcão e como co-orientador o Prof. Dr. Maurício Roberto da Silva. 
Escobar (1997), Kunz (1991), demonstram que a prática pedagógica da Educação Física nas escolas apresenta contradições entre as quais se destacam: a negação do conhecimento, a burla do tempo pedagógico, a avaliação de caráter excludente e punitiva, aulas sem planejamento, cisão entre teoria e prática, sexismo, prioridade dos conteúdos esportivos em detrimento dos demais conhecimentos produzidos pela humanidade. Estes estudos foram desenvolvidos no início da década de 1990, considerando o intenso debate dos anos de 1980 na área da Educação Física. Passaramse aproximadamente trinta anos e existem evidências de que tais contradições ainda não foram superadas e que, portanto, apesar das sugestões para o redimensionamento desta prática terem ocorrido, elas não foram implementadas como política pública para um programa de Educação Física na escola.

No atual panorama, o conteúdo ginástica, por exemplo, segundo Almeida (2005) apresenta condições ainda mais precárias, pois, além de tudo, tem sido excluído da escola, fruto também da (de) formação de professores de Educação Física, que, na maioria das vezes, nega esse conteúdo, ou o desenvolve de forma superficial e fragmentada, com ênfase em ginástica de academia e não na ginástica escolar. Assim, as evidências apontam para o agravamento da situação e, provavelmente, a inexistência de uma prática pedagógica articulada cientificamente para enfrentar as graves questões hoje colocadas na escola pública.

Um dos nossos primeiros procedimentos para nos apropriarmos do objeto de estudo foi, portanto, uma revisão de literatura, para responder o seguinte problema científico: Quais as proposições superadoras para o trato com o conhecimento da ginástica na escola são apresentadas pelo Coletivo de Autores (1992), Almeida (2005), Livro Didático Público de Educação Física da Secretaria de Estado da Educação do Paraná (2006) e Ayoub (2007)?

O estudo parte do campo da cultura corporal e das problemáticas significativas concretas da prática pedagógica nas aulas de Educação Física da escola, tendo como objetivo central explicitar possibilidades de alteração do trabalho pedagógico, no trato com o conhecimento da ginástica na escola, a partir de uma pesquisa bibliográfica. Para tanto, apresenta dois objetivos específicos: 1. sistematizar e reconhecer qual o conhecimento acumulado e reconhecido como conhecimento a ser tratado pela ginástica na escola, e 2. a partir da literatura, identificar princípios fundamentais para o trato 
com o conhecimento da ginástica na escola que possam contribuir para consubstanciar a materialização de experiências pedagógicas superadoras.

Considerando a problemática geral da pesquisa e a necessidade de reorganização do trabalho pedagógico na escola como um todo, apontamos como hipótese central do trabalho que a interação e articulação de princípios que constituem a organização do trabalho pedagógico como: trabalho como princípio educativo (trabalho material socialmente útil), a unidade teóricometodológica, e a auto-organização e autodeterminação dos estudantes, podem mudar significativamente a atual forma como está constituída a sala de aula e a escola. Assim, tanto a alteração no trato com a ginástica pode refletir na alteração do trabaIho pedagógico na escola, quanto a alteração do trabalho pedagógico na escola pode refletir no trato com o conhecimento ginástica.

Outro elemento importante a ser destacado, é a necessidade de avanços nos estudos, na produção de conhecimento no campo da ginástica, principalmente no que se refere à materialização de propostas com princípios educativos superadores. Para além das essenciais contribuições dos estudos históricos realizados - que nos possibilitam compreender a realidade - é fundamental que elas sirvam de embasamento para a intervenção na realidade comprometida com a transformação social, o que significa estar pautada em uma concepção de Educação Física que considere o homem ${ }^{3}$ como um ser histórico e social. Nesse sentido, o predomínio da abordagem técnica dos conteúdos da ginástica destituída da base sócio-político-cultural tem sido um dos limites para mudanças superadoras neste campo.

Portanto, considerando os limites para constituição de um artigo científico, os capítulos da dissertação foram reorganizados na tentativa de garantir os elementos centrais do estudo da seguinte forma: no primeiro tópico será tratada a questão da organização do trabalho pedagógico na escola capitalista, sendo apontada a necessidade de superação das contradições; o segundo tópico irá enfocar a ginástica a partir da matriz científica da história, destacando sua inserção no contexto escolar brasileiro; no terceiro tópico será apresentada a discussão sobre as possibilidades superadoras no trato com o conhecimento da ginástica a

3 A palavra "homem" será utilizada no texto com o sentido de humanidade, ser social. 
partir da produção do conhecimento; o quarto e último tópico trará a análise dos dados levantados e as conclusões finais.

\section{Organização do trabalho pe- dagógico na escola capitalista e a necessidade de sua trans- formação}

Antes de aprofundarmos as questões específicas referentes à prática pedagógica na escola, se faz necessário situá-la no contexto mais geral em que ela está inserida. Isso significa reconhecer de que escola estamos tratando e a que sistema político-econômico ela está servindo. Só assim, compreendendo os nexos e as determinações entre o sistema vigente e a escola, podemos entender como elas se expressam no interior dessa instituição, ou seja, como se organiza o trabalho pedagógico na escola capitalista. Desta forma, Freitas (1995) situa a organização do trabalho pedagógico da escola com a contradição da luta de classe e como essa se organiza nos diversos setores sociais. Isso significa que para compreender a organização do trabalho na escola capitalista, é preciso entender a organização do trabalho na sociedade capitalista.

Partindo dessa base referencial, é importante destacar que ao nos referirmos ao trabalho, o fazemos a partir da sua compreensão como categoria central, como fundamento da vida humana. É por meio do trabalho que o homem transforma a natureza para garantir a sua sobrevivência e ao mesmo tempo transforma a si mesmo (MARX, 1983). Contudo, tendo o real concreto como ponto de partida para entender a sociedade, é preciso reconhecer o duplo caráter que o trabalho assume na sociedade capitalista: o trabalho na perspectiva ontológica (ato fundante do ser social) versus o trabalho assalariado (trabalho abstrato - venda da força de trabalho). Dessa forma, o trabalho é subsumido pelo capital, que precisa ser reproduzido para se manter, caracterizando-se como um trabalho alienado, fragmentado, que não atende as demandas sociais.

Essa caracterização que o trabalho assume (fragmentado, alienado, mercadorizado) na sociedade em que vivemos, é refletida direta e indiretamente na escola em toda sua organização, quer seja na sua própria estrutura, na sua prática pedagógica, ou no seu projeto político-pedagógico. O trabalho pedagógico, na perspectiva de Freitas (1995) e Saviani (2005) é, portanto, o processo de materialização de um determinado projeto de educação através da atividade práxica de educadores e educandos organizados em relações determinadas, entre si e 
a sociedade. É o principal responsável pelo processo de humanização do homem pela educação.

Os princípios norteadores do trabalho pedagógico são formulados por uma teoria pedagógica - teoria essa, que sem a devida relação com a prática perde sua função, tornando-se apenas uma mera abstração. Vale ressaltar que a teoria pedagógica, por sua vez, está estritamente relacionada a uma teoria educacional que propaga uma concepção de educação respaldada em um projeto histórico de sociedade discutindo as relações entre educação e sociedade em seu desenvolvimento. Dessa forma, devemos estabelecer uma relação dialética entre projeto histórico - teoria educacional - teoria pedagógica - organização do trabalho pedagógico. É a partir desse entendimento que podemos identificar a organização do trabalho pedagógico como uma área no interior da teoria pedagógica, que expressa concretamente aquilo que é formulado na teoria. Ainda segundo Freitas (1995, p. 94), ele deve ser entendido em dois níveis: “a) como trabalho pedagógico que, no presente momento histórico, costuma desenvolver-se predominantemente em sala de aula; e b) como organização global do trabalho pedagógico da escola, como projeto político pedagógico da escola."
$\mathrm{Na}$ tentativa de aprofundarmos o debate sobre a caracterização da organização do trabalho pedagógico na disciplina curricular Educação Física e no intuito de identificar os limites e as possibilidades de superação do trabalho pedagógico na escola capitalista, iremos considerar duas categorias centrais: os objetivos/avaliação e o trato com o conhecimento.

Os objetivos gerais da educação são elementos fundamentais para se entender o trabalho na escola. Pistrak (2000), ao apresentar um contexto mais geral, afirma que é inconcebível o trabalho na escola sem que sejam considerados os objetivos gerais da educação. Freitas (1995), numa análise mais detalhada, aponta que os objetivos/ avaliação são uma categoria chave para compreender e transformar a escola, nos limites do atual momento histórico, porque é ela que modula as outras. O autor define objetivos e avaliação como "categorias que se opõem em sua unidade". Os objetivos apresentam o momento final a que se quer alcançar e a avaliação por sua vez, é o momento concreto em que se confronta o que foi objetivado anteriormente com os resultados obtidos. Assim, os objetivos da escola se expressam nas práticas de avaliação.

Considerando que vivemos numa sociedade de classes, os 
valores estimulados por esse sistema - competição, individualismo, punição, seleção - são incorporados pela escola que assume a função de preparar os indivíduos para os diversos campos de trabalho presentes na sociedade. Essa função que a escola capitalista assume é caracterizada por Freitas (1995) como função social seletiva. A essa função Snyders aponta que

De fato a seleção na escola é a projeção da divisão em nossa sociedade em classes; a escola é lugar de lutas de classes, não acredito que ela agrave, mas registra (e do mesmo modo confirma) as desigualdades de sucessos segundo as desigualdades sociais. (SNYDERS, 1988, p. 197).

Juntamente à categoria dialética objetivos/avaliação, o trato com o conhecimento é outro elemento importante a ser tratado nesse estudo para compreensão da organização do trabalho pedagógico na escola capitalista. Na sociedade capitalista em que o trabalho tornase estranho ao sujeito, onde o trabalhador não se reconhece e nem se apropria daquilo que produz, o trato com o conhecimento segue essa mesma diretriz. Apresenta-se de forma unilateral, fragmentado, prevalecendo a cisão entre teoria e prática como se fossem coisas opos- tas, isoladas que não estabelecem nenhuma relação. Contribuindo com essa reflexão, Freitas (1995) destaca a categoria dialética conteúdo/método da escola elencando três elementos centrais: a ausência do trabalho material socialmente útil, como princípio educativo; a fragmentação do conhecimento na escola; e a forma da gestão da escola.

No que se refere ao trabalho socialmente útil, o autor continua sua análise afirmando que o trabalho no interior da escola, o trabalho pedagógico é "trabalho desvinculado" da prática social em geral "porque é desvinculada do trabalho material" e caracteriza-se numa prática artificial que não é o trabalho vivo. Essas são contradições presentes na escola que precisam ser superadas na perspectiva de uma formação humana omnilateral. Ao nos referirmos à formação humana utilizamos a referência de Manacorda (1991, p. 81), em que o desenvolvimento da formação humana omnilateral deve ser entendido como "o chegar histórico do homem a uma totalidade de capacidades e, ao mesmo tempo, a uma totalidade de capacidades de consumo e gozo, em que se deve considerar, sobretudo o usufruir dos bens espirituais (plano cultural e intelectual), além dos materiais."

Considerando, portanto, os elementos tratados, Freitas define 
que a finalidade da organização do trabalho pedagógico deve ser

[...] a produção de conhecimento (não necessariamente original) por meio do trabalho com valor social (não do "trabalho" de faz-de-conta, artificial); a prática refletindo-se na forma de teoria que é devolvida à prática, num circuito indissociável e interminável de aprimoramento. (FREITAS, 1995, p. 100).

Assim, em contraposição ao trabalho alienado, artificial, é necessário assumir o trabalho material socialmente útil. Assumir o trabalho como elemento mediador fundamental entre professor/aluno e o conhecimento, e não mais o professor como mediador do conhecimento. Assumir a prática como ponto de partida e de chegada, para produção do conhecimento, estabelecendo forte relação com a teoria que a fundamenta, qualificando esse retorno "final" à prática em outro patamar. O trabalho na escola, como base da educação, deve estar ligado ao trabalho social, à produção real, a uma atividade concreta socialmente útil. Fora desse entendimento ele perderia seu valor essencial, seu aspecto social, reduzindo-se, de um lado, a aquisição de algumas normas técnicas, e, de outro, a procedimentos metodológicos capazes de ilustrar este ou aquele detalhe de um curso sistemático. (PISTRAK, 2000, p.38).

Outro fator fundamental para a concretização do trabalho socialmente útil é a auto-organização e autodeterminação dos estudantes. É como uma "escola de responsabilidades assumidas" (ESCOBAR, 1997) que vai desde a conservação da limpeza das instalações até a participação na administração financeira da instituição. Isso visa permitir que eles se organizem para participar da condução da sala e da escola de forma democrática, objetivando promover, fundamentalmente, no interior da escola, a experiência de formas democráticas de trabalho, decisivamente marcantes para sua formação.

Defendemos, portanto, que a interação e articulação desses princípios que constituem a organização do trabalho pedagógico: trabalho como princípio educativo (trabalho material socialmente útil), a unidade teórico-metodológica e a auto-organização dos estudantes, pode mudar significativamente a atual forma como está constituída a sala de aula e a escola. A educação deve ser compreendida também como uma forma de ação políticosocial, que não se limita a interpretar o mundo, mas que procura pela prática educativa, desenvolver uma ação transformadora do real. 
Aspectos do desenvolvimento da ginástica na história: reconhecendo o conhecimento a ser tratado pela ginástica na escola

A ginástica como conteúdo da Cultura Corporal, produzida historicamente pela humanidade, surge de necessidades sociais, reais e concretas e, em momentos históricos distintos, assume formas também distintas: desde a sobrevivência dos homens nos primórdios da humanidade; ao seu papel na formação integral; à preparação de guerreiros, à eugenização e higienização de povos; até os dias atuais. Assim, o surgimento do capitalismo como novo modo de produção, gerou uma nova forma de organização da sociedade e, conseqüentemente, novas necessidades a serem atendidas.

Os exercícios físicos na forma cultural de jogos, danças, ginástica, no âmbito escolar, surgem na Europa no final do século XVIII e início do século XIX, período da revolução industrial, no qual estava sendo constituída a sociedade capitalista, consolidando sistemas de ensino característicos da nova ordem vigente: a sociedade burguesa. Nessa época, o objetivo era utilizar o exercício físico para a formação de homens fortes e ágeis, uma vez que, o corpo sendo força de trabalho, era fonte de lucro para o novo sistema econômico da nova sociedade.

É, portanto, do início do século XIX que se pode apontar a origem da atual ginástica. No Brasil, esse processo de acúmulo e desenvolvimento das práticas corporais e da ginástica, em especial, não é diferente. A ginástica praticada no Brasil tem suas origens nas Linhas Ginásticas importadas da Europa e adotadas pelos militares.

Várias iniciativas para a inclusão da educação física nas escolas vão ocorrendo gradativamente por todo o país, sendo os exercícios ginásticos apontados como um dos meios mais importantes para tal finalidade: educar física e moralmente os indivíduos. Podemos afirmar sem receio que, durante muito tempo, aula de educação física na escola foi sinônimo de aula de ginástica. (AYOUB, 2007, P. 79).

Com o capitalismo já consolidado na Europa, é no final do Império que ocorrem profundas transformações no Brasil com o avanço da industrialização, o fim do sistema escravista, a chegada de força de trabalho imigrante e a ascensão dos militares. Goellner (1992) e Soares (2004) destacam que é neste processo de fortalecimento do poderio militar e de chegada de 
muitos imigrantes alemães no Brasil, que o Método Ginástico Alemão é implementado. Com caráter militarista, visando a formação de uma raça forte aos moldes do homem europeu - como defendiam os higienistas - logo disseminou-se pelo país a partir da segunda metade do século XIX. Foi incorporado como método oficial do exército brasileiro em 1860, e em 1870 no ensino primário, por meio do documento "Novo Guia para o Ensino de Ginástica nas Escolas Públicas da Prússia".

Na década de 1920, o Brasil adotou como método oficial de Educação Física, o Método Francês (Regulamento $\mathrm{n}^{\circ} 7$ - preparação de soldados), rompendo com a concepção Higienista e impulsionando a Educação Física Militarista. Nesse período, a Educação Física não tinha admitido um caráter pedagógico, era considerada apenas uma mera atividade prática, que visava à formação do 'cidadão-soldado', capaz de obedecer cegamente, servir e defender sua Pátria (GHIRALDELLI JUNIOR, 1988). O exercício ginástico, principalmente o de orientação militarista, constituiu-se, então, como a referência básica para o desenvolvimento da Educação Física na instituição escolar.

Após a Segunda Guerra Mundial, surgem novas tendências para a Educação Física escolar. O culto ao esporte-espetáculo ganha força no país e a identidade esportiva da Educação Física escolar é fortalecida pela pedagogia tecnicista, privilegiando o esporte de alto rendimento, a competição exacerbada. Assim, a concepção Desportiva Generalizada vai sendo consolidada na área da Educação Física e o esporte se firmando mundialmente como elemento predominante da cultura corporal. De acordo com o Coletivo de Autores (1992), até esse momento a Ginástica predominava como conteúdo da Educação Física escolar. A partir daí, o esporte é quem assume esse posto.

Em 1964, com a Ditadura Militar a Educação Física assume um caráter Competitivista. Seu objetivo primordial era amortecer a população (estudantil e trabalhadora) para perpetuar a dominação. Era preciso exterminar qualquer tipo de oposição que não aceitasse a continuidade do modelo político/ econômico vigente e para isso valorizava-se o desempenho esportivo nas competições, esquecendo do desempenho intelectual e profissional.

A partir do final da década de 1970 houve mudanças no rumo da Educação Física em um contexto de saída do regime militar e abertura política. Surgem aí os movimentos renovadores. Concepções que buscam uma fundamentação mais científica para a área e incorporam referenciais da Filosofia, Antropologia, Política, 
Sociologia, Psicologia e Pedagogia essenciais à prática pedagógica. Essas novas teorias tendem a ultrapassar os métodos tradicionais, questionando o processo de esportivização e apontando propostas superadoras para as aulas de Educação Física.

O contraditório, por outro lado, se verifica no fato de que apesar dos avanços teóricos, existem indícios de que a situação no interior da escola e das aulas de Educação Física ainda não evidencia avanços. De acordo com os estudos de Dieckert e Hildebrandt, a ginástica no Brasil, por exemplo, vem sendo predominantemente sistematizada pelo padrão esportivo e funcionalista, o que torna sua prática altamente especializada e fragmentada, limitando o seu potencial formativo e lúdico. Esses elementos contribuem, portanto, para que fora da escola ela venha cada vez mais se tornando um produto de consumo e seu acesso submetido à lógica de mercado.

Nesse processo, a ginástica sofre mutações, adquirindo novos padrões, novos sentidos e subjetividades e novos significados, sob as determinações do mercado. Com isso se introduzem na formação de professores e nas escolas, conhecimentos, métodos e técnicas desprovidos de significado cultural e de sentido pessoal. A lógica do consumo tem guiado o trato com o conhecimento nos currículos de formação em relação às exigências do mercado. A proliferação das academias de ginástica é exemplo típico. (ALMEIDA, 2005, p. 43).

A ginástica na escola não foge, portanto, à lógica de determinação do capital. A partir dos dados empíricos coletados nas pesquisas de Almeida (2005) e Ayoub (2007), pode-se constatar praticamente a ausência da Ginástica nos currículos escolares. Diversos fatores que contribuem para que a Ginástica seja cada vez menos praticada nas escolas são destacados pelas autoras.

Ayoub (2007, p. 81-82), primeiramente, traz o trabalho de Nista-Piccolo (1988, p. 121-124) como outra referência que também confirmou, na sua pesquisa, essa deficiência do conteúdo ginástica no âmbito escolar, especificamente em relação à ginástica artística (GA) e à ginástica rítmica desportiva (GRD). Depois disso, localiza principalmente dois aspectos que justificam essa negação da ginástica: a sua tradição de orientação militar e a sua associação à "ginástica espetacular." No primeiro caso, ressalta a resistência por parte dos profissionais da Educação Física que estavam participando das discussões 
mais amplas da década de 1980 em admitir que uma atividade com tamanha herança militar tivesse lugar numa escola democrática. $\mathrm{O}$ segundo aspecto refere-se à difusão da ginástica artística e da ginástica rítmica desportiva no Brasil a partir de 1970 e 1980 como atividades extremamente difíceis e, portanto, restritas aos atletas de alto nível.

O estudo de Almeida (2005, p. 81-89) aponta os seguintes indicadores para a exclusão da ginástica na escola: a) tendência à "esportivização"; b) a estrutura física e material das escolas encontra-se prioritariamente organizada para a prática esportiva; c) espaços e equipamentos inadequados ou inexistentes para a prática da ginástica; d) limitação do trato com o conhecimento da ginástica na formação de professores; e) ausência do conteúdo da ginástica na proposta pedagógica da disciplina Educação Física, no projeto político pedagógico da escola; f) utilização da ginástica, apenas, como atividade recreativa, aquecimento ou condicionamento físico para o desenvolvimento de outras atividades esportivas.

Essa situação em que se encontra a ginástica na escola, constatada nas pesquisas, aponta para a necessidade de se enfrentar o problema. A ausência da ginástica enquanto conhecimento organizado e sistematizado limita as referências e experiências dos alunos da escola pública no que se refere à cultura corporal e, conseqüentemente, limita sua formação enquanto ser social, produtivo e criativo. Portanto, a ginástica como conteúdo da Educação Física na escola, é um conhecimento fundamental que não pode ser negado. Sua legitimidade no currículo escolar brasileiro se faz presente na medida em que

[...] permite ao aluno a interpretação subjetiva das atividades ginásticas, através de um espaço amplo de liberdade para vivenciar as próprias ações corporais. No sentido da compreensão das relações sociais, a ginástica promove a prática das ações em grupo onde, nas exercitações como "balançar juntos" ou "saltar com os companheiros", concretiza-se a "co-educação", entendida como forma particular de elaborar/praticar formas de ação comuns para os dois sexos, criando um espaço aberto à colaboração entre eles para a crítica ao "sexismo" socialmente imposto." (COLETIVO DE AUTORES, 1992, p. 77-78).

É com base nessa perspectiva transformadora que consideramos que a prática pedagógica constituída pelo processo de problematizar situações a partir do real para que o conhecimento seja apreendido de 
forma coletiva através do trabalho, é uma possibilidade a ser concretizada nas aulas de Educação Física. Isto exige um esforço integrado entre universidade e escola, na perspectiva de uma educação para a emancipação dos indivíduos, seu reconhecimento como sujeitos históricos capazes de intervir para transformar a realidade existente.

Desta forma, os conhecimentos da ginástica, juntamente com outros conhecimentos escolares, deverão contribuir para que o aluno possa constatar interpretar, compreender, explicar e intervir de maneira crítica e autônoma na realidade social em que vive (COLETIVO DE AUTORES, 1992), tendo como horizonte teleológico a formação omnilateral. Enfim, a cultura, por ser socialmente construída, pode também ser socialmente configurada para outras possibilidades educativas:

Minha escola: uma alegria que brota de um encontro com as obras de arte, desde os grandes poemas de amor até as realizações científicas e técnicas, de uma tensão em direção aos mais realizados sucessos humano, de uma participação, de um certo modo de participação nos movimentos organizados pelo que os homens se esforçaram para progredir em seus estilos de vida (SNYDERS, 1988, p. 13).
Considerando, portanto, todo esse contexto em que a prática pedagógica da Educação Física e da ginástica está inserida - de uma escola organizada a partir do trabalho alienado, tendo o esporte de alto rendimento como conteúdo primordial a ser tratado, com poucos espaços e equipamentos adequados para as práticas corporais, com a uma formação de professores deficiente - podemos apontar para a grande defasagem na escolarização dos jovens e crianças no que tange a Educação Física. Isso significa que não estão sendo dominados os conhecimentos científicos próprios do campo da cultura corporal, não estão sendo desenvolvidas habilidades nem competências globais - técnica, científica, pedagógica, ética e política - para aplicar tais conhecimentos em situações concretas de vida, o que torna esses sujeitos alienados e passivos frente à realidade. A segregação sexista, racista e a segregação em função das aptidões e qualidades físicas ainda é uma prática predominante nas aulas de ginástica prevalecendo a máxima do "culto ao corpo". Dessa forma, negar espaços, tempos, conhecimentos, orientações, a partir da escola, também no campo da cultura corporal, é submeter o povo à ignorância e este é um dos maiores crimes morais contra uma nação. "Nos cabe perguntar pela 
política cultural de educação de uma nação que se quer soberana, independente, com um povo feliz" (TAFFAREL, 2006).

\section{O trato com o conhecimento ginástica na escola: proposi- ções superadoras a partir da produção do conhecimento}

Nos capítulos anteriores foram apresentados elementos fundamentais para o estudo sobre o trato com o conhecimento da ginástica na escola. Após situar a discussão a partir das relações mais gerais do modo de produção, do contexto escolar, da organização do trabalho pedagógico na escola capitalista e de problematizar a ginástica ao longo do processo histórico com sua inserção no contexto educacional brasileiro, nesse capítulo serão abordadas, mais especificamente, algumas obras que apresentam princípios e possibilidades de alteração do trato com o conhecimento da ginástica escolar.

Para tanto, é preciso delimitar, inicialmente, que esse estudo ao reconhecer as contradições existentes e ao mesmo tempo a necessidade de superá-las, baseouse na teoria do conhecimento que subsidia essa análise a partir do real concreto, qual seja, o Materialismo Histórico Dialético.
O método parte da prática social, compreendendo a ação humana como uma construção histórica. Para tanto, serão utilizadas leis e categorias para a apreensão da realidade. As categorias são essenciais para esse estudo, como explicação das leis gerais que nos permitem apreender o real. Dessa forma, foram delimitadas para o trabalho as categorias: realidade/ possibilidades e organização do trabalho pedagógico - trato com o conhecimento.

Para atingir os objetivos traçados, os procedimentos investigativos foram delimitados em torno da pesquisa qualitativa, do tipo bibliográfica, abarcando a análise das seguintes obras: Coletivo de Autores (1992); Almeida (2005); Ayoub (2007); Livro Didático Público de Educação Física da Secretaria de Educação do Estado Paraná (2006). Para a delimitação das fontes a serem analisadas foram definidos como critérios, estudos que tratam da questão da Ginástica Escolar e proposições para o ensino da ginástica na escola.

Explicitados os critérios e as obras a serem analisadas, diante de tantas confusões, e até mesmo, apropriações de conceitos para atender a determinados interesses de classe, é preciso ressaltar que ao tratar de proposições superadoras para o trato com o conhecimento 
da ginástica, estamos nos baseando na concepção crítico-superadora da Educação Física sistematizada na obra do Coletivo de Autores (1992). Esta perspectiva se propõe a constatar a realidade, interpretar, compreender, explicar e intervir novamente no real, ou seja, ela parte do real e retorna a ele estabelecendo sempre uma nova síntese. Defende o homem como sujeito histórico e, portanto, responsável por intervir na realidade para transformá-la, em busca de uma sociedade socialmente referenciada, em busca da emancipação humana. Compreende a Educação Física como uma prática pedagógica, uma disciplina escolar com conteúdos próprios e de relevância científica e social para a formação dos sujeitos.

Nesse sentido, todas as obras apresentadas apontam princípios e possibilidades para o trato com o conhecimento ginástica de forma mais ou menos aprofundada, no seu âmbito geral da educação e específico da Educação Física. O fazem, retomando o processo histórico em que a ginástica se desenvolveu do seu surgimento aos dias atuais, e, assim, partindo da realidade concreta, constatam as contradições presentes no trabalho pedagógico, e em especial, o processo de exclusão da ginástica na escola. Os dados levantados permitiram reconhecer essas contradições como fatores limitantes para o desenvolvimento das potencialidades do ser humano, e, portanto, a urgente necessidade de sua superação.

Na tentativa de aprofundar a discussão - sem, contudo, ter a menor pretensão de esgotá-la -, trataremos, a seguir, das contribuições apresentadas nesses quatro trabalhos.

COLETIVO DE AUTORES. Metodologia do ensino da Educação Física. São Paulo: Cortez, 1992.

O Coletivo de Autores (1992) é uma obra central nesse estudo. Além de ser referência para o que entendemos por proposições superadoras, é também referência para todos os outros estudos analisados aqui. Apesar de não aprofundar os conteúdos específicos da Educação Física, até porque esse não é o seu objetivo, apresenta princípios gerais e uma proposta sistematizada para o trato com esse conhecimento.

O livro aborda questões teórico-metodológicas da disciplina curricular Educação Física, e traz a tona a defesa da cultura corporal como objeto de estudo, com uma proposta sistematizada de seus conteúdos: ginástica, esporte, jogos, acrobacia, mímica, lutas e outros. Busca subsidiar a elaboração, tanto de uma teoria pedagógica, quanto de programas específicos. 
Alguns princípios curriculares no trato com o conhecimento são destacados no livro: a) a relevância social do conteúdo que "implica em compreender o sentido e o significado do mesmo para a reflexão pedagógica escolar" (COLETIVO DE AUTORES, 1992, p. 31), devendo estar vinculado à realidade concreta e possibilitar a compreensão das determinações históricas; b) adequação às possibilidades sócio-cognoscitivas do aluno - adequar o conteúdo à capacidade cognitiva e a prática social do aluno; c) simultaneidade dos conteúdos enquanto dados da realidade - confronto à idéia de etapismo e hierarquização dos conteúdos, tratando-os a partir da relação que mantêm entre si como dados da mesma realidade que não podem ser explicados de forma isolada. Esse princípio é chamado por Pistrak (2000) de organização do conhecimento por meio de sistema de complexos; d) princípio da espiralidade da incorporação das referências do pensamento rompe com a idéia de linearidade com que é tratado o conhecimento na escola, buscando "compreender as diferentes formas de organizar as referências do pensamento sobre o conhecimento para ampliá-las" (idem, p. 33). Esse princípio fundamenta a proposta de organização do conhecimento a partir de ciclos de escolarização; e) provisoriedade do conhecimento - rompe com a idéia de naturalização das coisas, reconhecendo que a produção humana é datada historicamente, $\mathrm{e}$ que, portanto, cada modo de produção da vida, determina, em última instância, a constituição de uma sociedade e seu desenvolvimento científico.

Vale ressaltar, entretanto, que o trato com o conhecimento não pode destacar o conteúdo de forma isolada. Precisa sempre estar articulado ao par dialético conteúdo/método. A proposta apresentada pelo Coletivo de Autores (1992) para organizar esse conteúdo na escola são os ciclos de escolarização: o primeiro é o ciclo da organização da identidade dos dados da realidade (da pré-escola à $3^{\text {a }}$ série); o segundo ciclo é o de iniciação à sistematização do conhecimento (da $4^{\mathrm{a}}$ à $6^{\mathrm{a}}$ série); o terceiro é o ciclo de ampliação da sistematização do conhecimento ( $7^{\mathrm{a}}$ e $8^{\mathrm{a}}$ séries); e, o quarto ciclo é o de aprofundamento da sistematização do conhecimento (ensino médio).

Ao reconhecer a legitimidade da ginástica nos programas de Educação Física, os autores a entendem como

[...] uma forma particular de exercitação onde, com ou sem uso de aparelhos, abre-se a 
possibilidade de atividades que provocam valiosas experiências corporais, enriquecedoras da cultura corporal das crianças, em particular, e do homem, em geral. (COLETIVO DE AUTORES, 1992, p. 77)

Destacam, ainda, que essas atividades devem compor todos os ciclos de escolarização nos seus diferentes graus de complexidade, considerando, para tanto, os seus fundamentos básicos: saltar - desprender-se da ação da gravidade, manter-se no ar e cair sem machucar-se; equilibrar - permanecer ou deslocar-se numa superfície limitada, vencendo a ação da gravidade; rolar/girar - dar voltas sobre os eixos do próprio corpo; trepar subir em suspensão pelos braços, com ou sem ajuda das pernas, em superfícies verticais ou inclinadas; e, balançar/embalar -impulsionarse e dar ao corpo um movimento de "vaivém".

A metodologia nessa perspectiva deve possibilitar que o aluno apreenda este conteúdo específico e suas relações com a prática social. Uma abordagem problematizadora é fundamental nesse processo. Como forma de contribuir para materializar esses princípios apresentados, o livro traz exemplos sistematizados de organização do conteúdo da ginástica nos ciclos e traz também exemplo de uma aula e de como estruturar uma aula de ginástica.

ALMEIDA, Roseane Soares. A Ginástica na escola e na formação de professores. 2005. 157 f. Tese (Doutorado em Educação) - Faculdade de Educação, Universidade Federal da Bahia, Salvador, 2005.

Passamos à análise da tese de doutorado de Almeida (2005), intitulada "A Ginástica na escola e na formação de professores", referenciada na concepção crítico-superadora da Educação Física, que tem como objeto de estudo a ginástica como conteúdo da cultura corporal.

Em sua pesquisa de campo a autora constatou a ausência do conteúdo ginástica na escola. Almeida (2005) considera que este conteúdo não se apresenta como conhecimento alicerçado em uma consistente base teórica, mas sim, de ser um conhecimento que se apresenta diluído e fragmentado na formação de professores.

Portanto, seu trabalho teve como objetivo propor elementos teórico-metodológicos para enfrentar as contradições da exclusão/inclusão da ginástica na escola. Procurou elucidar as mediações, contradições e as possibilidades de superação da lógica excludente e alienante. Tendo como base o debate teórico, os 
dados empíricos da escola pública e do curso de formação de professores da FACED/UFBA, a autora analisou uma possibilidade concreta de enfrentar as contradições, se valendo de uma experiência desenvolvida na disciplina Ginástica Escolar da FACED/UFBA. A grande relevância do trabalho está, portanto, no reconhecimento de que existem, sim, possibilidades de essência para alterar a organização do trabalho pedagógico e a lógica do trato com o conhecimento da ginástica, mas que essas possibilidades devem estar pautadas na perspectiva de enfrentamento da lógica formal e da sociedade de classes.

Partindo dessa base referencial e desse projeto desenvolvido como proposta concreta de ensino na escola e na formação de professores, Almeida (2005) destaca a necessidade de se considerar alguns princípios e possibilidades superadoras para o trato com o conhecimento da ginástica: a) a manifestação e a clareza de eixos curriculares referenciados em um projeto histórico socialista; b) tomar como pressuposto o trabalho como categoria fundante do ser social, que ao se expressar na escola como trabalho pedagógico deve se contrapor à lógica da alienação com o trabalho socialmente útil; c) a reconceptualização da definição de objetivos e avaliação da escola, do currículo, do ensino e da aprendizagem, no sentido de colocar este par dialético no centro da formação do professor de Educação Física e do currículo escolar, selecionando os conteúdos conforme o seu significado social; d) a autodeterminação e auto-organização do coletivo dos estudantes para Ihes permitir o aprendizado de formas democráticas de trabalho em contraponto às formas autoritárias próprias do trabalho alienado. O desenvolvimento da auto-organização e autodeterminação dos sujeitos é condição para a formação humana, pois é pela apropriação ativa do conhecimento que é possível construir a humanização; e) a construção coletiva da unidade teórico-metodológica e a organização curricular a partir do sistema de complexos temáticos como formas de enfrentamento da fragmentação do conhecimento; f) a proposta metodológica de organização do conhecimento em ciclos de ensino, baseada na proposta do Coletivo de Autores (1992); g) organização do tempo pedagógico de forma a superar a dimensão temporal da aula. No processo de construção social do conhecimento pode ser incentivado uma outra organização do tempo pedagógico em oficinas, seminários integrados e interativos e festivais da cultura corporal, por exemplo.

Mais especificamente sobre os conhecimentos tratados 
nas aulas da disciplina Ginástica Escolar, o estudo aponta a gênese e o desenvolvimento da ginástica na história até os dias atuais, as bases da ginástica (apoios e giros - com suas diversas possibilidades de ação), os cinco fundamentos da ginástica (saltar, equilibrar, embalar, trepar e rolar), as ajudas e tomadas de segurança, o domínio da técnica, o conhecimento reconhecido como ginástica e suas possibilidades superadoras.

Outros aspectos importantes tratados também nas aulas foram o uso das referências teóricometodológicas para o ensino da ginástica, o uso do conhecimento científico para tratar as questões específicas da ginástica, as oficinas dos fundamentos e bases da ginástica como possibilidade de superar a forma tradicional única de aula expositiva/demonstrativa centralizada no professor, a construção de conceitos a partir de experiências da prática buscando superar a dicotomia teoria/prática, o processo de tomada de decisão dos acadêmicos para coordenarem oficinas nas escolas, a construção de materiais alternativos para as aulas de ginástica, mas ao mesmo tempo a luta por equipamentos adequados e condições dignas de trabalho, a avaliação por meio de processos auto-avaliativos e processuais visando superar a avaliação excludente e punitiva, predominantes na educação formal. Enfim, a dedicação aos estudos é ressaltada como condição imprescindível para uma formação consistente do futuro professor.

Portanto, a ginástica precisa se desenvolver com uma consistente base teórica - científica, pedagógica, técnica, ética, moral e política - aliada a uma "teoria educacional emergente do trabalho revolucionário e quotidiano da classe trabalhadora" (ALMEIDA, 2005, p. 147).

AYOUB, Eliana. Ginástica geral e educação física escolar. 2 ed. Campinas, SP: Editora da Unicamp, 2007.

O trabalho elaborado por Ayoub (2007) é resultado dos estudos de doutorado em Educação Física na FEF/Unicamp desenvolvidos em 1998 e publicado, posteriormente, em forma de livro com modificações do texto original, inclusive com a ampliação de algumas reflexões realizadas naquele momento.

O estudo está articulado ao Grupo de Pesquisa da FEF/ Unicamp - Grupo Ginástico da

4 Maiores informações sobre o GGU, consultar o site do Grupo - www.ggu.com.br -, ou buscar suas pesquisas no site da Biblioteca Digital da Unicamp - http://libdigi.unicamp.br/. 
Unicamp (GGU) ${ }^{4}$ - que ao longo dos seus vinte anos de existência foi consolidando e fundamentando as suas produções e experiências no que se refere à Ginástica Geral. Souza (1997), coordenadora do grupo, destaca que a concepção de Ginástica Geral do grupo está pautada na abordagem SócioCultural da Educação Física que aponta a necessidade da Educação Física de facilitar a apropriação dos elementos da cultura corporal que fazem parte de cada grupo social. Complementa, ainda, que nesta perspectiva, o importante é o "ser do homem e não o fazer" (SOUZA, 1997, p. 81).

A partir dessa referência, a autora apresenta a Ginástica Geral como

uma manifestação da cultura corporal, que reúne as diferentes interpretações da Ginástica (Natural, Construída, Artística, Rítmica, Desportiva, Aeróbica, etc.) integrando-as com outras formas de expressão corporal (Dança, Folclore, Jogos, Teatro, Mímica, etc.), de forma livre e criativa, de acordo com as características do grupo social e contribuindo para o aumento da interação social entre os participantes. (PÉREZ GALLARDO; SOUZA, 1995, p. 292 apud SOUZA, 1997, p. 88).
Como conteúdo da Ginástica Geral, o GGU destaca as seguintes manifestações da cultura corporal: as ginásticas, as danças, os esportes, as lutas, os jogos e brincadeiras, as artes musicais, as artes cênicas, as artes plásticas e as experiências de vida.

Pautada nessa base referencial, Ayoub (2007) publica o livro intitulado de "Ginástica geral e educação física escolar", apresentando como objetivos centrais compreender como a Ginástica Geral (GG) vem se manifestando na sociedade contemporânea e discutir suas perspectivas para a Educação Física escolar.

O ponto central da discussão será a partir da proposta de Ginástica Geral defendida pela autora. Dessa forma, após levantar todos esses elementos para a contextualização da GG, Ayoub (2007), no intuito de apresentar elementos que componham uma identidade para Ginástica Geral, aponta que:

- Considera positiva a utilização do termo "Ginástica Geral" como forma de referir à ginástica em geral, à essa manifestação de diversos tipos de ginástica com caráter não competitivo e com a participação de todos. Além de destacar que a universalização do termo GG pode facilitar o diálogo entre as diferentes nações. 
- Defende que a GG não é simplesmente o retorno da ginástica desenvolvida no passado - como afirmam alguns estudiosos -, mas uma articulação entre esses aspectos, os da ginástica científica e das diversas manifestações da ginástica atual. Significa considerar ao mesmo tempo a importância da reconstrução do lúdico e do desenvolvimento do conhecimento científico, uma necessária relação entre lúdico, artístico, científico e técnico.

Ao considerar a composição da GG a partir dessa articulação, a autora define, então, que o eixo fundamental da GG é a ginástica. Outras manifestações da cultura corporal como o jogo, a dança, a luta, o esporte podem e devem estar interligados, mas sua base é a ginástica. Sem a intenção de dicotomizar esses conteúdos, mas de caracterizá-los reconhecendo o que os identifica e o que os diferencia, é que são definidos um conjunto de elementos constitutivos da ginástica: elementos corporais, exercícios acrobáticos e exercícios de condicionamento físico (com, sem e em aparelhos) (AYOUB, 2007, p. 74)

Para fundamentar o que Ayoub (2007) chama de caráter "transformador" da GG, a autora destaca três características que po- dem potencializar esse processo: a) a GG como prática não competitiva pode gerar um espaço de resistência aos valores da ginástica de competição e, consequentemente, o questionamento da visão capitalista de sociedade; b) a GG aberta a participação de todos pode constituir-se em um espaço privilegiado para a vivência lúdica; e c) o caráter demonstrativo da GG, principalmente por meio dos festivais, possibilita o desenvolvimento de trabalhos em grupo e pelo grupo.

A Ginástica Geral como conhecimento a ser estudado na Educação Física escolar deve abarcar elementos do núcleo primordial da ginástica, da ginástica científica e das diversas manifestações gímnicas contemporâneas. Isso significa que as diferentes formas de manifestação gímnica poderão e deverão ser tema das aulas de GG.

Aprender ginástica geral na escola signi-
fica, portanto, estudar, vivenciar, conhe-
cer, compreender, perceber, confrontar,
interpretar, problematizar, compartilhar,
apreender as inúmeras interpretações da
ginástica para, com base nesse aprendiza-
do, buscar novos significados e criar novas
possibilidades de expressão gímnica.
Sob essa ótica, podemos considerar que
a ginástica geral, como conhecimento a
ser estudado na educação física escolar,
representa a Ginástica. (AYOUB, 2007,
p. 87)

Nesta perspectiva de reconstrução da ginástica na Educação Física na escola, Ayoub (2007) toma como referência duas propostas que vêm sendo desenvolvidas na Faculdade de Educação Física da Unicamp: a 
proposta da professora Nista-Piccolo (1995) e a proposta do GGU (PÉREZ GALLARDO; SOUZA, 1997; SOUZA, 1997, p. 83-95). A autora destaca, portanto, nas referidas propostas os seguintes princípios norteadores: a) valorizar as experiências dos alunos, buscando ampliá-las no processo educativo; b) desafiar os alunos a experimentarem novas possibilidades de ação, por meio da superação dos próprios limites; c) conduzir a ação pedagógica em parceria com os alunos, que devem ser reconhecidos como "sujeitos co-responsáveis e co-autores do processo educativo"; d) incentivar a utilização de materiais, ginásticos ou não, tradicionais ou não, estimulando a descoberta de possibilidades de ação; e) desenvolver a criatividade; f) proporcionar o trabalho em grupo; g) desenvolver a capacidade de decisão e ação; h) planejar, organizar, pensar e repensar o contexto da aula; i) papel do professor como estimulador e orientador; j) considerar a GG como "espaço aberto de ação" - referenciado pelos estudos do Grupo de Trabalho Pedagógico UFPe-UFSM (1991) - a partir de seis perspectivas: GG como algo socialmente regulamentado, GG como algo a ser aprendido, GG como algo a ser assistido, GG como algo a ser refletido, GG como algo a ser demonstrado e GG como algo a ser transformado.
Estes princípios estão pautados na concepção de aulas abertas desenvolvida por Hildebrandt e Laging (1986) e pelo Grupo de Trabalho Pedagógico UFPe-UFSM e na referência de Paulo Freire que defende a ação educativa como um processo dialógico-cooperativo. Foi referenciada nestes princípios, que Ayoub (2007) elaborou uma proposta de intervenção para a GG na escola pública.

Portanto, a relevância deste estudo está em, por um lado, contribuir para o avanço dos estudos sobre a ginástica e a Ginástica Geral em específico, sob a perspectiva crítica, ao reconhecê-la como um dos conhecimentos significativos que precisa ser tratado pela Educação Física escolar. E por outro, contribuir com a reflexão e a materialização de proposições transformadoras no que se refere à ginástica na escola. Vale ressaltar, ainda, a importância e as contribuições do trabalho desenvolvido pelo GGU para a ginástica e a Ginástica Geral nos âmbitos nacional e internacional.

SECRETARIA DE ESTADO DA EDUCAÇÃO DO PARANÁ. Livro Didático Público - Educação Física, ensino médio. 2 ed. Curitiba: SEED-PR, 2006.

O Estado do Paraná, por meio da sua Secretaria de Estado da 
Educação, produziu um livro didático público para o ensino médio no ano de 2006. O livro foi construído com a participação dos professores da rede estadual de ensino na perspectiva de subsidiar educadores e educandos do ensino médio no trato com o conhecimento da cultura corporal. Para o aprofundamento da obra, serão tratados a seguir da sua organização, dos conteúdos que aborda e da forma como o conhecimento ginástica é tratado.

Um primeiro ponto a ser destacado são as cartas, sendo uma do Secretário de Estado da Educação e outra específica aos estudantes. Ambas demonstram o comprometimento do livro com os interesses das amplas massas, afirmando que o conhecimento é construído pelo conjunto da humanidade e que, portanto, deve ser de domínio público. Alerta também sobre o tipo de sociedade na qual estamos inseridos, qual seja, a capitalista, portanto, dividida em classes.

A organização do livro está em consonância com a estrutura apresentada no livro do Coletivo de Autores (1992), tratando esporte, jogos, ginástica, lutas e a dança, como "conteúdos estruturantes" da Educação Física. A partir destes, há subdivisões que abarcam outros conhecimentos que estabelecem relações e nexos com o conteúdo principal. No caso específico, a
Educação Física é tratada como disciplina escolar, ou seja, um componente do currículo que é reconhecida como um campo do conhecimento com conteúdos próprios que precisam ser legados às gerações presentes e futuras.

Adentraremos na análise das propostas sugeridas a partir do conteúdo estruturante ginástica. Para tal, nos baseamos em outros elementos apontados no livro, tais como, a história, ao considerá-la como fio condutor no desenvolvimento da humanidade, na luta desta pela sua sobrevivência, tendo a práxis como eixo norteador da proposta. Ao historicizar a ginástica, não a faz de maneira aleatória, mas em consonância com o contexto econômico-político-social, ou seja, é datado e explicado historicamente. Portanto, estabelecendo os nexos para a compreensão dos fenômenos.

O conteúdo estruturante ginástica está subdividido em: 1) Introdução; 2) O circo como componente da ginástica; 3) Ginástica: um modelo antigo com roupagem nova? Ou uma nova maneira de aprisionar os corpos?; 4) Saúde é o que interessa? $\mathrm{O}$ resto não tem pressa!; 5) Os segredos do corpo.

É utilizada uma linguagem direta, objetiva, com gravuras de quadros de pintores famosos sobre a temática, excertos de outras 
referências de livros, sítios, filmes. Enfim, não tem a pretensão de esgotar o tema, mas subsidiar o acesso à ampliação do conhecimento sobre as temáticas tratadas. Há inclusive, panfletos sobre as temáticas.

Destacamos também como propostas encontradas no livro, a construção de materiais alternativos e de como utilizar os mesmos (passo-a-passo), com desenhos ilustrativos. Há o incentivo à utilização de outros materiais, aparelhos e equipamentos para a realização das atividades, principalmente em grupo. Vale ressaltar, que as atividades são propostas do nível mais simples para o mais complexo e ainda, que em determinadas situações haja a presença do professor, uma vez que algumas exercitações requerem mais orientações e segurança.

Identificamos o constante estímulo à pesquisa, considerando a história da humanidade como matriz científica. $\mathrm{O}$ incentivo à discussão de temas contemporâneos, relacionando-os ao contexto mais geral da sociedade e ao contexto específico da Educação Física, também está presente.

Por fim, compreendemos que este livro é a concretização de propostas superadoras no momento em que aponta as atividades, explicita como se faz e, principalmente, considera a história da humanidade para compreender o passado, fazer o presente e planejar o futuro, não de forma linear ou mecanicista, mas de forma dialética, tendo como mola propulsora a contradição. Esse material se diferencia dos demais estudos aqui analisados pela dimensão e pelo acesso a ele, que vai desde os estudantes das escolas públicas e universidades, aos professores e gestores públicos.

Ao implementar tal empreitada, vale ressaltar, no entanto, que por se pautar em um perspectiva histórica que contraria a lógica e os interesses da classe dominante, o livro foi alvo de duras críticas por parte de alguns meios de comunicação, que alegavam inadmissível o caráter ideológico do material. Assim, como se fosse possível a neutralidade científica, o livro foi alvo de desqualificações e perseguições. Ao mesmo tempo, há que se destacar a mobilização de professores e estudantes de todo o país, dos mais diversos níveis de ensino em defesa do livro didático público por reconhecerem sua importância política e pedagógica no âmbito educacional.

\section{Princípios e possibilidades de alteração do trato com o conhecimento da ginástica na escola: uma síntese final}

Apresentadas as idéias principais das obras e autores analisados, 
considerando o objetivo central deste estudo, serão destacadas principalmente as questões referentes aos princípios e possibilidades de alteração do trabalho pedagógico e, especificamente, do trato com o conhecimento da ginástica na escola. Destacaremos a seguir os elementos que aproximam e os que distanciam as diferentes proposições.

As obras apresentam em comum os seguintes princípios, mais específicos, que devem consubstanciar proposições superadoras: exploração/experimentação das possibilidades corporais com e sem aparelhos; construção de materiais e exploração de suas possibilidades de ação; trabalho coletivo; a valorização das experiências dos alunos, buscando ampliá-las no processo educativo; a prática do planejamento e síntese avaliativa ao final das aulas; o desenvolvimento da autonomia, da criatividade; a importância do acesso ao conhecimento científico; o direito e necessidade de acesso aos bens culturais produzidos pela humanidade; a articulação do conhecimento e o trato com os elementos da cultura corporal nas aulas de Educação Física para além do conteúdo esportivo, a fim de formar sujeitos críticos e autônomos capazes de intervir na realidade.

Esses são, portanto, alguns princípios e possibilidades de construção de uma práxis superadora da ginástica elitizada, contrária ao sexismo, seletivismo, competitivismo, individualismo socialmente impostos, que vise legitimar a ginástica como fator enriquecedor da cultura. Ao entendermos a cultura como uma construção social e histórica, por meio do trabalho, reconhecemos a sua possibilidade de ser também socialmente configurada para outras possibilidades educativas.

Todas as obras analisadas defendem a cultura corporal como objeto de estudo da Educação Física, porém partem de concepções diferenciadas. O Coletivo de Autores (1992), Almeida (2005) e o Livro Didático Público de Educação Física da Secretaria de Estado da Educação do Paraná (2006) partem da perspectiva crítico-superadora e do materialismo histórico dialético como método. Já Ayoub (2007), se fundamenta na perspectiva sóciocultural da Educação Física apoiada nos autores Pérez Gallardo, Souza e Nista-Piccolo. Esta orientação aponta a necessidade da Educação Física de facilitar a apropriação dos elementos da cultura corporal que fazem parte de cada grupo social.

Portanto, as obras do Coletivo de Autores (1992), Almeida (2005) e o Livro Didático Público de Educação Física da Secretaria de Estado da Educação do Paraná (2006) que partem da perspectiva 
teórica do materialismo histórico dialético e da abordagem críticosuperadora da Educação Física, propõem: trabalho como princípio educativo, a superação da fragmentação do conhecimento e a auto-organização dos estudantes. Por outro lado, Ayoub (2007) não defende o trabalho como princípio educativo, mas o sujeito como elemento principal.

Dessa forma, ao destacar os elementos comuns e divergentes das obras analisadas reconhecemos que no trabalho realizado por Ayoub (2007), apesar da autora constatar as contradições presentes na prática pedagógica da Educação Física na escola e de defender que a cultura corporal precisa ter um caráter transformador, a mesma não explicita qual projeto histórico a orienta. Isto leva ao entendimento de que essa transformação pode ser alcançada plenamente ainda na sociedade capitalista, na sociedade de classes. Essa é uma divergência presente a ser pontuada, pois consideramos que a transformação deve ser construída nos planos imediato, mediato e histórico. Significa dizer que as ações na escola como forma imediata de alterar o trabalho pedagógico, e em especial, o trato com o conhecimento da ginástica, por exemplo, para terem plenamente seus objetivos alcançados precisam estar articuladas a um projeto histó- rico de sociedade. Nesse sentido, defendemos que as proposições superadoras estejam relacionadas com a construção de uma sociedade sem classes.

Vale ressaltar, no entanto, que não estamos apontando que apenas a explicitação desses elementos é suficiente, que o discurso por si só é suficiente. Apenas a prática social concreta poderá garantir coerência entre o ideal e o real e assim, garantir a materialização de propostas superadoras - o que, é preciso reconhecer, está presente em todas as obras analisadas. Contudo, identificamos que diante dos avanços do capital e da sua hegemonia, a apropriação e socialização de teorias do conhecimento que se coloquem na luta de resistência contra esse modo de produção explorador é também fundamental.

Em que pesem as diferenças apresentadas na análise das obras, não se pode negar o avanço desses estudos no campo crítico da Educação Física. É preciso reconhecer que todas elas ao identificarem as contradições presentes no trabalho pedagógico na escola e na ginástica, em especial, se propõem a enfrentar o problema a partir de estudos científicos e da implementação de experiências, assumindo o compromisso em defesa da escola pública.

É preciso deixar claro que nossa intenção nesse trabalho não 
é desconsiderar ou desqualificar os estudos produzidos que não estejam pautados na mesma matriz científica. Nossa intenção é estabelecer um debate aberto e franco frente àqueles que reconhecemos como grandes referências na luta para recolocar a ginástica como conhecimento extremamente relevante na escola e na formação dos sujeitos. Nossa intenção é estabelecer um debate científico frente ao que entendemos ser uma possibilidade concreta de alteração do que está posto. Esse exercício do estudo e da crítica, no sentido de avançarmos juntos para alterar essa cruel realidade de franca decomposição e degeneração do modo do capital produzir a vida, consideramos fundamental para todos aqueles que têm o compromisso com o ser humano, com a educação pública, gratuita, laica e para todos.

Portanto, a partir do estudo realizado foi possível identificar que existe, sim, uma outra maneira de se tratar o conhecimento na escola. Podemos, dessa forma, confirmar nossa hipótese de que a partir de determinados princípios e proposições superadoras no trato com o conhecimento da ginástica, este pode contribuir para a alteração da escola. Ao passo que a alteração do trabalho pedagógico na escola também contribui para a alteração do trato com o conhecimento da ginástica.
Desta forma, cabe também à ginástica, como conteúdo da cultura corporal, e à Educação Física, como disciplina curricular, uma área de formação, contribuir para o desenvolvimento do pensamento científico, a partir da prática social, e apontar possibilidades de transformação do trabalho pedagógico na escola. A ginástica como conteúdo da cultura corporal produzida socialmente e acumulada historicamente precisa ser acessada por todos. A ginástica por si só não tem como enfrentar as contradições do sistema capitalista, mas pode sim, estar alinhada em um contexto de resistência e de luta concreta pela transformação social, na perspectiva da construção da sociedade socialista.

\section{Referências}

ALMEIDA, Roseane Soares. A Ginástica na escola e na formação de professores. 2005. 157 f. Tese (Doutorado em Educação) - Faculdade de Educação, Universidade Federal da Bahia, Salvador, 2005.

AYOUB, Eliana. Ginástica geral e educação física escolar. 2 ed. Campinas, SP: Editora da Unicamp, 2007.

COLETIVO DE AUTORES. Metodologia do ensino da Educação Física. São Paulo: Cortez, 1992. 
ESCOBAR, Micheli Ortega. Transformação da didática: construção da teoria pedagógica como categorias da prática pedagógica: experiência na disciplina escolar educação física. 1997. 195 f. Tese (Doutorado em Educação) - Faculdade de Educação, Universidade Estadual de Campinas, Campinas, 1997.

FREITAS, Luiz Carlos de. Crítica da organização do trabalho pedagógico e da didática. Campinas, SP: Papirus, 1995.

GHIRALDELLLI JR, Paulo. Educação Física Progressista: a pedagogia crítico social dos conteúdos e a Educação Física Brasileira. São Paulo: Loyola, 1988.

GOELLNER, Silvana Vilodre. O Método Francês e a Educação Física no Brasil: da caserna a escola. 1992. 215p. Dissertação (Mestrado em Ciências do Movimento Humano) - Escola Superior de Educação Física, Universidade Federal do Rio Grande do Sul, Porto Alegre, 1992.

HILDEBRANDT, Reiner; LAGINF, Ralf. Concepções abertas no ensino da Educação Física. Rio de Janeiro: Ao Livro Técnico, 1986.

KUNZ, Elenor. Educação física: ensino \& mudanças. Ijuí: Ed. UNIJUÍ. 1991.

LANGLADE, Alberto; LANGLADE, Nelly. Teoria General de
La Gimnasia. Buenos Aires: Stadium, 1970.

MANACORDA, Mario Alighiero. A. Marx e a pedagogia moderna.

São Paulo: Cortez; Autores Associados, 1991.

MARX, Karl. O Capital: crítica da economia política. 3 ed. v. I, t. I. São Paulo: Nova Cultural, 1983. PISTRAK, Moisey Mikhaylovich.

Fundamentos da escola do trabalho. São Paulo: Expressão Popular, 2000.

SAVIANI, Demerval. Escola e democracia. 37 ed. Campinas, SP: Autores Associados, 2005.

SECRETARIA DE ESTADO DA EDUCAÇÃO DO PARANÁ. Livro Didático Público Educação Física, ensino médio. 2 ed. Curitiba: SEEDPR, 2006. (também disponível em: http://www.seed.pr.gov. $\mathrm{br} /$ portals/livrodidatico/frm resultadobuscalivro.php)

SNYDERS, George. A Alegria na escola. São Paulo: Edictora Manole LDTA, 1988.

SOARES, Carmem Lúcia. Educação

Física: raízes européias e Brasil. 3. ed. Campinas, SP: Autores Associados, 2004.

SOUZA, Elizabeth Paoliello Machado de. Ginástica Geral: uma área do conhecimento da Educação Física. 1997. 163f. Tese (Doutorado em Educação Física) - Faculdade de Educação 
Física, Universidade Estadual de Campinas. Campinas, 1997.

TAFFAREL, Celi Nelza Zulke. O "letramento" na Educação Física. Rascunho Digital FACED/UFBA, Salvador: BA, 2006. Disponível em: $<$ www.faced.ufba.br/rascunho digital/> (Celi Zulke Taffarel). Acesso em: 21 mar. 2009.

TAFFAREL, Celi Zülke; ESCOBAR, M. O. Cultura corporal e os dualismos necessários a ordem do capital. Rascunho Digital FACED/UFBA, Salvador: BA, 2006. Disponível em: <www. faced.ufba.br/rascunho digital/> (Celi Zulke Taffarel). Acesso em: 12 jan. 2009.

TRIVIÑOS, Augusto Nibaldo Silva. Introdução à pesquisa e ciências sociais: a pesquisa qualitativa em educação. SP: Atlas, 1987.

\begin{abstract}
The study presents as an object propositions overcoming for the teaching of the gymnastics in the school, from the organization of the pedagogic work - treatment with the knowledge. Is to indicate possibilities for changing pedagogical work, in the treatment with the knowledge of the gymnastics in the school, from a qualitative inquiry examining the works: Coletivo de Autores (1992), Almeida (2005), Ayoub (2007), Public text book of Physical Education of the Paraná (2006). The results make possible us to recognize that, though of the obvious contradictions, is possible to contribute to alter the pedagogic work in the school from determined beginnings and propositions overcoming in the treatment with the knowledge of the gymnastics.
\end{abstract}

Keywords: Propositions overcoming; Gymnastics; School.

Recebido: fevereiro/2011. Aprovado: julho/2011. 